\title{
SEM, FTIR, DRX and Micro Activity Study of the V and Ni Influence on the Activity of Zeolyte Cracking Catalysts.
}

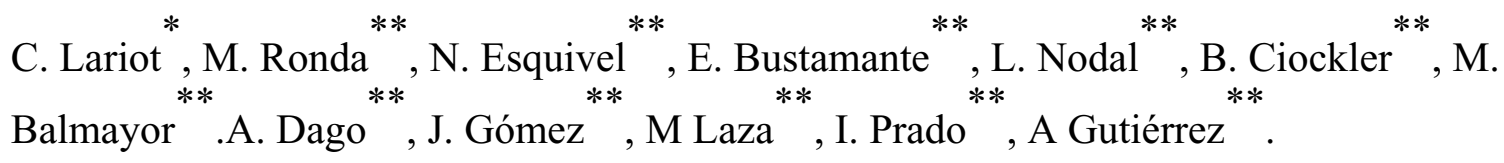

National Centre for Scientific Research (CNIC). P.O. Box 6414. C. Havana. Cuba.

Petroleum Research Institute (CEINPET). Washington y Churruca. Cerro. Havana. Cuba.

odelsa@infomed.sld.cu

The combination of higher demand of light petroleum derivates, like gasoline and diesel, with insufficient delivery of regular injects to the catalytic cracking plant, bring high expectative over the properties of cracking catalysts of heavy injects and the process residuals. The control of metal poisoning effect, with vanadium and nickel, on the activity of these zeolytic catalysts is very important in this case [1, 2]. Scanning electron microscopy (SEM) [3, 4], Fourier transformed infrared spectrometry (FTIR), X ray diffraction (DRX) [3-5] and micro activity tests were employed in the analysis of this poisoning effect.

Size, aggregation degree, contamination and morphology changes of catalyst particles determined by SEM, besides the complete analytical data, allows to correlate them with the lost of aluminium and the poisoning process in the zeolytic catalyst during the deactivation process.

It was shown that the more active catalyst had the higher poisoning sensitivity. Lost in crystallinity were not detected by DRX but the diminish of " $\mathrm{a}_{\mathrm{o}}$ " net cell parameter at the first 4 hours of the deactivation process. The diminish of the intensity of $400-700 \mathrm{~cm}^{-1}$ and $900-1100 \mathrm{~cm}^{-1}$ FTIR bands with the time during the process is in accordance with aluminium lost and structural changes in the catalyst (changes in the zeolyte $\mathrm{Si} / \mathrm{Al}$ ratio).

SEM images of catalysts deactivated in water vapour impregnate with $\mathrm{V}$ and $\mathrm{Ni}$ at $750^{\circ} \mathrm{C}$, are in accordance with those results. Big irregular particles aggregates near $200 \mu \mathrm{m}$ and little round particles of 20-25 $\mu \mathrm{m}$ diameter, like fresh catalyst typical micro spheres, were seen in electron micrographs (Fig. 1). It was also proved catalyst particle size growth after hidro thermal treatment. Besides, it was seen little particles near $5 \mu \mathrm{m}$ diameter with crystalline appearance on the surface of deactivated catalyst particles (Fig.2). This little particles may be related with the impregnated V and Ni that can be responsible for the catalyst deactivation.

[1] R. R. Edison et al. Oil and Gas Journal, Dec. 20 (1976), 55.

[2] B. B. Agrawal, I. B. Gulati. Petroleum and Hydrocarbons, 6, 4, (1976), 55.

[3] G. Gianneti, A. Montes, G. Rodríguez. "Zeolitas. Características, propiedades y aplicaciones industriales”. Edit. Innov. Tecnol. Fac. Ing. UCV, Venezuela, (2000).

[4] P. Gelin, C. Cueguen. Applied Catalysis, 38, (1988), 225.

[5] J.A. Rabo. Zeolite Chemistry and Catalysis. Chap. 2, (1976). 


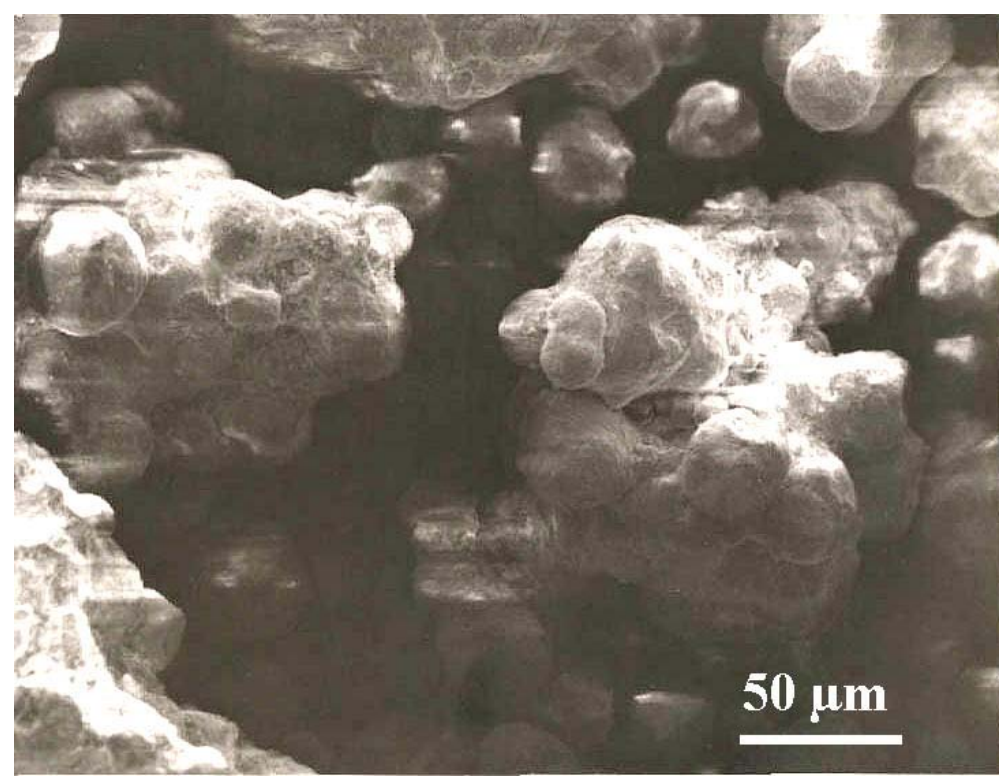

Fig. 1: Particle aggregates and round isolated particles.

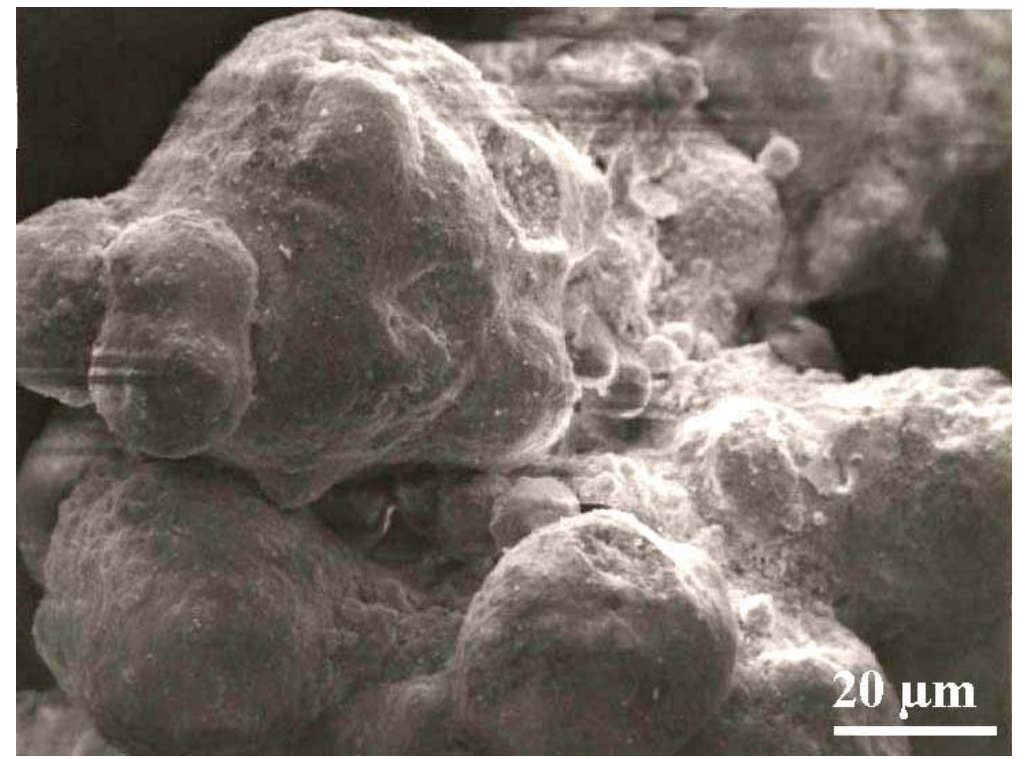

Fig. 6: Little particles on the catalyst particles surface with crystalline appearance 